\title{
The possible protective effects of virgin olive oil and Nigella sativa seeds on the biochemical and histopathological changes in pancreas of hyperlipidaemic rats
}

\author{
L.M. Aboul-Mahasen ${ }^{1,2}$, R. Abdulrahman Alshali \\ ${ }^{1}$ Anatomy Department, Faculty of Medicine, King Abdulaziz University, Jeddah, Saudi Arabia \\ ${ }^{2}$ Anatomy Department, Faculty of Medicine, Al-Azhar University, Cairo, Egypt \\ [Received: 1 January 2019; Accepted: 3 February 2019]
}

Background: Hyperlipidaemia is a risk factor for the development and progression of atherosclerosis and is linked to various diseases. This study was done to evaluate the possible protective effects of virgin olive oil and Nigella sativa seeds on the biochemical and histopathological changes which occurred in the pancreas of the rats. The study lasted 8 weeks and included 24 albino rats that were divided into four groups (6 rats each); Group I - control group, fed with normal standard diet, Group II - fed with high fat diet (HFD), Group III — fed with HFD and virgin olive oil, Group IV - fed with HFD and Nigella sativa seeds powder.

Materials and methods: After finishing the experiment, blood samples were collected and assessed for the lipid profile, fasting blood glucose, pancreatic amylase and insulin levels. Then, the rats were sacrificed and the pancreata were extracted and slices of them were processed for histological examination using haematoxylin stain and Masson's trichrome stain. Small fragments from the tail of the pancreata were extracted and processed for electron microscopic examination. The statistical analysis of the data using the appropriate statistical tests was also conducted.

Results: In the present study, the serum lipid profile in hyperlipidaemic rats was ameliorated in rats fed on high fat diet with virgin olive oil or Nigella sativa seed powder, which was reflected by a significant decrease in total cholesterol, low-density lipoprotein-cholesterol and triglycerides. Moreover, Nigella sativa decreased high-density lipoprotein (HDL), while virgin olive oil significantly increased HDL. Also a significant decrease in the serum levels of blood glucose and amylase and a significant increase in insulin levels were present in these groups. The histological and ultrastructural results revealed regeneration of the exocrine and endocrine parts of the pancreatic tissues from the hyperlipidaemic rats fed with virgin olive oil or Nigella sativa seeds. Conclusions: In this study, the biochemical results were paralleled to the histological and ultrastructural results; therefore, it could be concluded that virgin olive oil and Nigella sativa seeds had antihyperlipidaemic and hypoglycaemic effects and they could protect the pancreas from hyperlipidaemia-induced injury. Daily consumption of virgin olive oil and Nigella sativa seeds in the diet is highly recommended. (Folia Morphol 2019; 78, 4: 762-772)

Key words: pancreas, virgin olive oil, Nigella sativa seeds, hyperlipidaemia, pancreatitis 


\section{INTRODUCTION}

Nowadays, with the exciting lifestyle, people less frequently eat fresh fruits and green vegetables that enforce their antioxidant and immunity status. Moreover, high-fat diet and insufficient physical activity are factors contributing to the development of hyperlipidaemia, which is a major risk factor for the development of atherosclerosis and is highly related to many diseases [5].

Virgin olive oil is an efficient food with several nourishing elements such as monounsaturated fatty acids. Also, it is a great source of phytochemicals, containing polyphenolic compounds $[26,36]$. It is healthier to increase the consumption of monounsaturated fatty acids (MUFA) replacing the polyunsaturated fatty acids (PUFA), because it lowers the risk of atherosclerosis as it reduces the circulating lipoprotein's sensitivity to peroxidation [10].

Virgin olive oil is an essential ingredient of the Mediterranean diet and is appreciated worldwide because of its nutritional benefits in metabolic diseases, including type 2 diabetes. It augments the key risk factors for cardiovascular disease, for instance the blood pressure, glucose metabolism, lipoprotein and antithrombotic profiles $[1,10]$. Clinical studies provided evidence that consumption of olive oil might lower the risk of heart disease by lowering blood cholesterol levels and reducing low-density lipoprotein (LDL) cholesterol oxidation [7].

These outcomes are attributed beside the MUFA to the minor compounds of virgin olive oil such as hydrocarbons, polyphenols, tocopherols, sterols, triterpenoids and other nutrients. Most of these components have certified antioxidant properties and hypolipidaemic and anti-inflammatory effects [32, 33]. Furthermore, diet enriched with MUFA prevents central body fat distribution and decreases postprandial adiponectin expression induced by a carbohydrate-rich diet in insulin-resistant individuals [34].

Nigella sativa seed (N. sativa) is a plant cultured in many countries in the Mediterranean region and Asia. It is known as "Sannouj, Habbat el Baraka or Black seed". Nigella sativa "black seeds" has long been used as a nice flavour added to variety of Persian cuisine, such as salads, pastries and bread, pickle and sauces [34]. Organic composition of N. sativa seeds includes oil, carbohydrate, fibres, proteins and saponins. The fixed oil composition of N. sativa includes linoleic acid, oleic acid, arachidic acid, eicosadienoic acid, palmitic acid, stearic acid and myristic acid [21]. The major phenolic compounds of $\mathrm{N}$. sativa seeds are $\mathrm{p}$-cymene (37.3\%), thymoquinone (13.7\%), carvacrol $(11.77 \%)$, carvone $(0.9 \%)$, and thymol $(0.33 \%)$ [31].

The active constituent of $\mathrm{N}$. sativa, which is principally thymoquinone, has potential therapeutic properties; it exhibits anti-inflammatory effects on several inflammatory disorders including encephalomyelitis, colitis, oedema and arthritis through suppression of prostaglandins and leukotrienes as inflammatory mediators [9]. Nigella sativa seeds have also antihistaminic and antidiabetic activities and are used traditionally for treatment of asthma, cough, bronchitis, headache, rheumatism, fever, and influenza [14].

Nigella sativa seeds are well-known also for their potent antioxidative effects. Some studies demonstrated that $\mathrm{N}$. sativa seeds might preserve significantly the spatial cognitive ability in rats challenged with chronic cerebral hypoperfusion [6, 19].

Since virgin olive oil and $\mathrm{N}$. sativa seeds are commonly used in the diets of Mediterranean countries and Asia and there is little data about plants which has both hypoglycaemic and hypolipidaemic effects, the aim of this study is to evaluate the possible protective effects of virgin olive oil and N. sativa seeds on the biochemical and histopathological changes which may occur in the pancreas of the rats fed with high-fat diets.

\section{Ethical approval}

This study was conducted according to guidelines and protocols approved by the ethical committee for animal care and use in King Fahd Medical Research Centre (KFMRC), KAU, Jeddah, Saudi Arabia, which are in accordance with the guidelines of the Canadian Council on Animal Care.

\section{MATERIALS AND METHODS}

Virgin olive oil and Nigella sativa seeds were purchased from the local traditional market, Jeddah, KSA.

\section{Experimental animals}

The albino rats weighing 180-230 g were obtained from the Animal Experimental Unit of King Fahd Medical Research Centre, King Abdul Aziz University, Jeddah, KSA. The rats were housed in well-aerated cages in an animal room and maintained in a temperature-controlled room $\left(24^{\circ} \mathrm{C} \pm 1{ }^{\circ} \mathrm{C}\right)$ with a $12 \mathrm{~h}$ light $/ 12 \mathrm{~h}$ dark cycle, $55 \% \pm 10 \%$ humidity. They were fed with normal standard diet and water ad libitum. 


\section{Induction of hyperlipidaemia}

The albino rats fed with high-fat diet (HFD) in the form of butter, in a dose of $20 \mathrm{~g} / 100 \mathrm{~g} \mathrm{(20 \% )}$ of diet [38] for 8 weeks. After 3 weeks, blood samples were taken for lipid profile analysis to ensure the occurrence of hyperlipidaemia.

\section{Experimental design}

A total of 24 rats were used in the study for 8 weeks. The albino rats were divided into four groups $(n=6)$ : - Group I (G1) - control group, which was fed with normal standard diet and used as reference;

- Group II (G2) - hyperlipidaemic (non-treated) group, fed with HFD in a dose of $20 \mathrm{~g} / 100 \mathrm{~g}$ (20\%) of diet [38];

- Group III (G3) - fed with HFD and virgin olive oil. The animals received $1.5 \mathrm{mg} / \mathrm{kg}$ of virgin olive oil every day by intragastric intubation [25];

- Group IV (G4) - fed with HFD and Nigella sativa seeds powder. The seeds were powdered and dissolved in freshly prepared water and the animals received $300 \mathrm{mg} / \mathrm{kg}$ everyday by intragastric intubation [17].

\section{Blood analysis}

Blood samples were taken after 8 weeks from the beginning of the experiment. Blood samples were collected and the sera of all groups were immediately frozen and stored at $-70^{\circ} \mathrm{C}$ until analysed for different bio-chemical analyses including triglycerides, cholesterol, high density lipoprotein (HDL), LDL, glucose, pancreatic amylase and insulin.

Concentrations of different parameters in sera were determined by enzymatic immuno-assay methods using the following kits for measurements:

- Rat Low Density Lipoprotein (LDL), Elisa Kit (My BioSource com, San Diego, USA, Catalogue No. MBS702165);

- Rat High Density Lipoprotein (HDL), Elisa Kit (My BioSource.com, San Diego, USA, Catalogue No. MBS2505957);

- Rat Triglyceride (TG), Elisa Kit (My BioSource.com, San Diego, USA, Catalogue No. MBS005097);

- Rat Quick Detect TM Total Cholesterol, Elisa Kit (My BioSource.com, San Diego, USA, Catalogue No. MBS846775);

- Rat Glucose, Elisa Kit (My BioSource.com, San Diego, USA, Catalogue No. MBS7233226);

- Rat Pancreatic Alpha Amylase (AMYa), Elisa Kit (My BioSource.com, San Diego, USA, Catalogue No. MBS750781);
- Rat Insulin, Elisa Kit (Thermo Scientific, USA, Catalogue No. 743022717).

\section{Technique of histological study}

The rats were anaesthetised lightly by diethyl ether inhalation and the abdominal cavity was incised at the midline. The pancreata were removed and specimens were fixed by immersion in formaldehyde $10 \%$ for 3 days. The specimen were dehydrated in ascending grades of ethyl alcohol and cleared in benzene. The specimens were soaked for three changes in paraffin and were finally embedded in paraffin wax. A microtome was used to cut the paraffin blocks into serial transverse sections at thickness of $6-8 \mu \mathrm{m}$. The sections were attached to an albumenised glass slides. They were stained with haematoxylin and eosin (H\&E) stain to study the general structure and with Masson's trichrome stain to demonstrate the collagen fibres in the pancreas [8]. Slides were photographed using a light microscope (BX51, Olympus, Tokyo, Japan) compatible with an Olympus digital camera, Anatomy Department, Faculty of Medicine, KAU, KSA).

\section{Technique of transmission electron microscopic study}

Small fragments from the tail of the pancreata were extracted. Samples were fixed by immersion in $5 \%$ phosphate buffered glutaraldehyde ( $\mathrm{pH} 7.3)$. The tissue pieces were post-fixed in $1 \%$ buffered osmium tetroxide. Then, specimens were dehydrated, cleared and embedded in Epon 812 [16]. Semithin sections ( $1 \mathrm{~mm}$ thick) were stained with $1 \%$ toluidine blue in borax for light microscopy at the Regional Mycology and Biotechnology Centre, Al-Azhar University, Cairo, Egypt. Selected areas were trimmed down for ultrathin sectioning. Ultrathin sections (60a $\mathrm{nm}$ ) were cut, doubly stained with uranyl acetate and lead citrate [18] and examined using a transmission electron microscope (JEOL 1010 EX II, Japan) at the electron microscopic unit, Ain Shams University, Cairo, Egypt.

\section{Statistical analysis}

The data were statistically analysed using SPSS statistical software, version 19.0 (SPSS Inc., Chicago, IL, USA) for Windows. The results were presented as means \pm standard deviations (SD). The differences between the continuous data were analysed using one-way ANOVA. Data was presented as means \pm SD. Differences were considered statistically significant when $\mathrm{p}<0.05$. 
Table 1. Effects of virgin olive oil and Nigella sativa seed supplementation on blood lipid profile, glucose, pancreatic amylase and insulin in rats

\begin{tabular}{lcccc}
\hline & $\begin{array}{c}\text { Group I } \\
\text { (control) }\end{array}$ & $\begin{array}{c}\text { Group II } \\
\text { (HFD) }\end{array}$ & $\begin{array}{c}\text { Group III } \\
\text { (HFD + olive oil) }\end{array}$ & $\begin{array}{c}\text { Group IV } \\
\text { (HFD + Nigella sativa seeds) }\end{array}$ \\
\hline Triglycerides [mg/dL] & $72.5 \pm 5.3^{* * *}$ & $107.69 \pm 1.4$ & $77.69 \pm 1.39^{* * *}$ & $60.69 \pm 1.4^{* * *}$ \\
Cholesterol [mg/dL] & $84.4 \pm 3.1^{* * *}$ & $212.53 \pm 2.7$ & $103.53 \pm 3^{* * *}$ & $100.53 \pm 2.62^{* * *}$ \\
LDL-C [mg/dL] & $47.6 \pm 0.6^{* * *}$ & $151.87 \pm 2$ & $51.87 \pm 2.42^{* * *}$ & $64.87 \pm 2.4^{* * *}$ \\
HDL-C [mg/dL] & $29.4 \pm 0.5^{* * *}$ & $40.01 \pm 0.2$ & $37.01 \pm 0.19^{* * *}$ & $25.01 \pm 0.19^{* * *}$ \\
Glucose [mg/dL] & $89.7 \pm 2.2^{* * *}$ & $197.84 \pm 2$ & $144.84 \pm 1.9^{* * *}$ & $123.84 \pm 1.85^{* * *}$ \\
Pancreatic amylase [U/L] & $85.7 \pm 2^{* * *}$ & $153.72 \pm 2$ & $119.72 \pm 2.8^{* * *}$ & $77.72 \pm 2.17^{* * *}$ \\
Insulin [mc IU/mL] & $3.76 \pm 0.1^{* * *}$ & $1.23 \pm 0.2$ & $3.42 \pm 0.2^{* * *}$ & $3.63 \pm 0.5^{* * *}$ \\
\hline
\end{tabular}

Data are expressed as mean \pm standard deviation $(n=6)$. All values are significantly different as compared with untreated hyperlipidaemic rats; ${ }^{* * *} p<0.001 ; H F D-$ high fat diet; HDL-C — high-density lipoprotein cholesterol; LDL-C — low-density lipoprotein cholesterol

\section{RESULTS}

\section{Biochemical results}

Lipid profile. Table 1 shows that serum levels of triglyceride, cholesterol and LDL in G2 fed on HDL were significantly higher than those of $\mathrm{G} 1(\mathrm{p}<0.001)$. The rats in G3 (fed on HFD and virgin olive oil) and G4 (fed on HFD and N. sativa seeds) showed a significant decrease $(p<0.001)$ in the serum levels of triglycerides, cholesterol and LDL as compared with G2.

Fasting blood glucose concentration. Table 1 shows that fasting blood glucose (FBG) concentration in serum of $G 2$ was increased significantly $(p<0.001)$ as compared with control G1. The rats in G3 and G4 showed a significant decrease $(p<0.001)$ in FBG as compared with G2.

Serum pancreatic amylase. Table 1 shows that the mean serum amylase level in rats in $G 2$ increased significantly as compared with the control rats $(p<0.001)$. In G3 and G4 it decreased significantly $(p<0.001)$ as compared with G2.

Serum insulin concentration. Table 1 shows that the mean serum insulin level in $\mathrm{G} 2$ decreased significantly as compared with the control rats $(p<0.001)$. In G3 and G4 it increased significantly $(p<0.001)$ as compared with $\mathrm{G} 2$.

\section{Histological results}

Microscopic examination of H\&E-stained sections from the pancreata of control rats (Group I) revealed a normal pancreatic architecture which is organised into lobes and lobules (Fig. 1a). The pancreas was formed of exocrine and endocrine parts. The acini represented the exocrine part and islets of Langerhans represented the endocrine part.
The acini had different sizes and shapes and most of them were formed of a single row of pyramidal cells which have dark basophilic nuclei and apical acidophilic zymogen granules (Fig. 2a). The islets of Langerhans appeared as noncapsulated pale stained rounded or oval areas with regular outlines inside the pancreatic lobules. They were composed of mainly red beta-cells and few peripheral dark alpha-cells. Beta-cells formed most of the density of the islet and occupied the central and peripheral regions of the islet (Fig. 3a).

Sections from the pancreata of Group II rats (fed on HFD) showed a marked thickening and congestion of intralobular blood vessels with widening of intralobular ducts (Fig. 1b). The cytoplasm of the pancreatic acini contained many vacuoles and most of their nuclei showed a marked degree of degeneration as they were small, dark and pyknotic (Fig. 2b). Most of islets of Langerhans lost their regular outlines with a marked reduction in their sizes and numbers. Most of beta-cells appeared degranulated with small degenerated nuclei (Fig. 3b). Sections from the pancreata of Group III rats (fed on HFD and virgin olive oil) showed that the pancreas nearly restored its normal structure (Fig. 1c). The pancreatic acini were moderately improved in shape and most of them had no vacuolation (Fig. 2c). Most of nuclei and zymogen granules appeared nearly similar to those of control rats. The islet of Langerhans appeared somewhat similar to the control group and most of beta-cells in the central and peripheral regions of the islet with normal density (Fig. 3c).

Sections from the pancreata of Group IV (rats fed on HFD and N. sativa seeds) were nearly similar to 

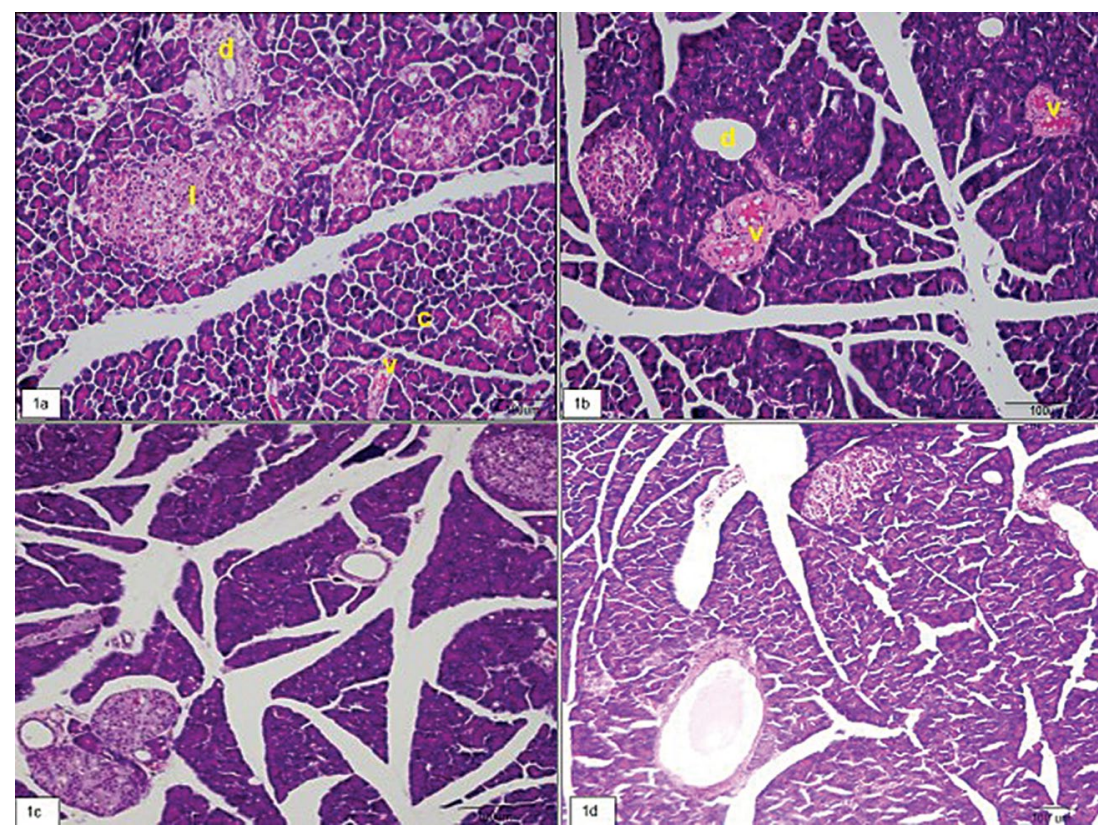

Figure 1. Photomicrographs of transverse sections from the rat pancreas of: a. Group I (control) showing the normal pancreatic structure. The exocrine acini (c), endocrine islets of Langerhans's (I), intralobular blood vessels (V) and ducts (d); b. Group II (fed with HFD) showing a marked thickening and congestion of intralobular blood vessels (V) with widening of intralobular ducts (d); c. Group III (fed with HFD and virgin olive oil) showing that the pancreas nearly restored its normal structure; d. Group IV (fed with HFD and Nigella sativa seeds) showing that it is nearly similar to control group. H\&E; scale bar $=100 \mu \mathrm{m}$.
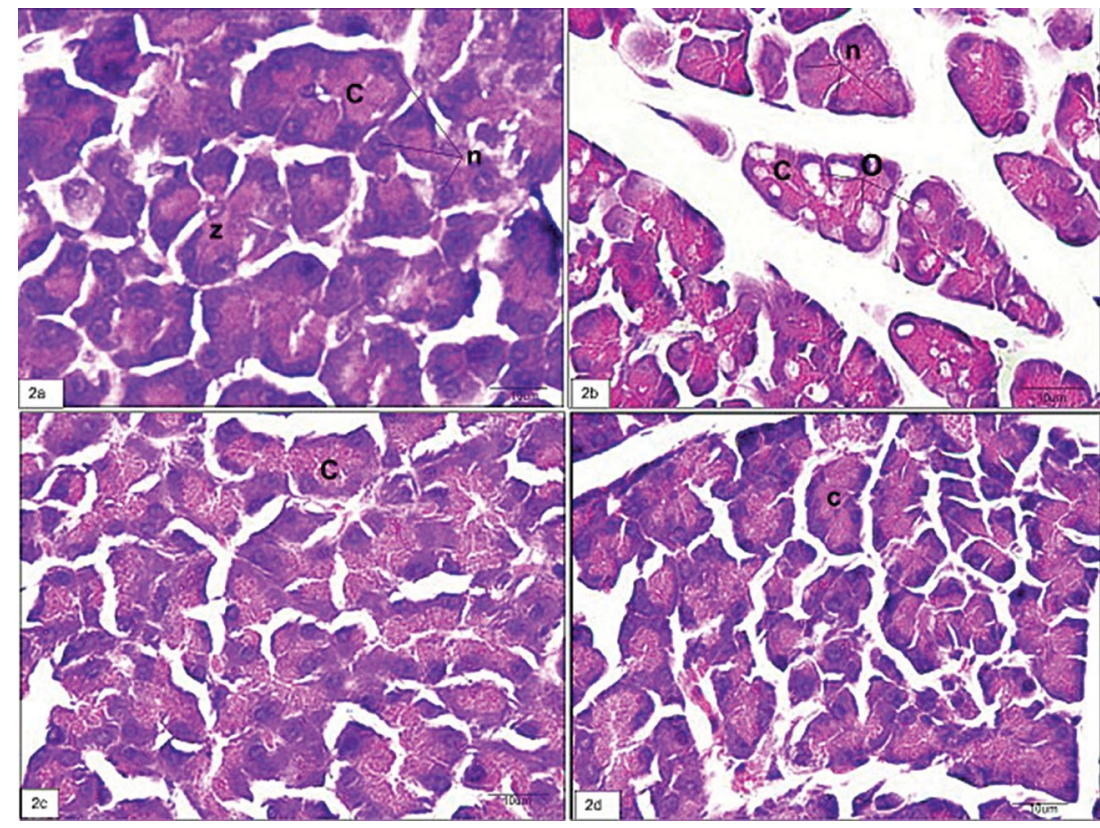

Figure 2. Photomicrographs of transverse sections from the rat pancreas of: a. Group I (control) showing the acini (C) have different sizes and shapes. Each acinus is formed of a single row of pyramidal cells which have dark basophilic nuclei ( $\mathrm{n}$ ) and apical acidophilic zymogen granules (Z); b. Group II (fed with HFD) showing that the acinar cytoplasm (C) containing many vacuoles (0). Most of the nuclei (n) showing a marked degree of degeneration; $\mathbf{c}$. Group III (fed with HFD and virgin olive oil) showing the pancreatic acini $(C)$ are a moderately improved in shape and most of them had no vacuolation; d. Group IV (fed with HFD and Nigella sativa seeds) showing the pancreatic acini (C) are markedly improved in shape with no vacuolation. H\&E; scale bar $=10 \mu \mathrm{m}$. those of the control group (Fig. 1d). The pancreatic acini were markedly improved in shape with no vacuolation (Fig. 2d). The nuclei and zymogen granules appeared nearly similar to those of control rats. The islet of Langerhans appeared nearly similar to control group with nearly regular outlines. The beta-cells appeared with normal density in the central and peripheral regions of the islet (Fig. 3d).

In sections stained with Masson's trichrome from the pancreata of control group, a normal distribution of collagen fibres as appeared as fine collagen fibres in the interlobular septa and around the acini. The collagen fibres are surrounded the interlobular vessels and ducts. Mild collagenous fibrous content appeared incompletely surrounding the islets of Langerhans (Fig. 4a). In sections from the pancreata of Group II fed on HFD, thick collagenous fibres appeared surrounding the dilated interlobular vessels and ducts. Large areas of haemorrhage appeared (Fig. 4b). In sections from the pancreata of Group III fed on HFD and virgin olive oil and from Group IV fed on 

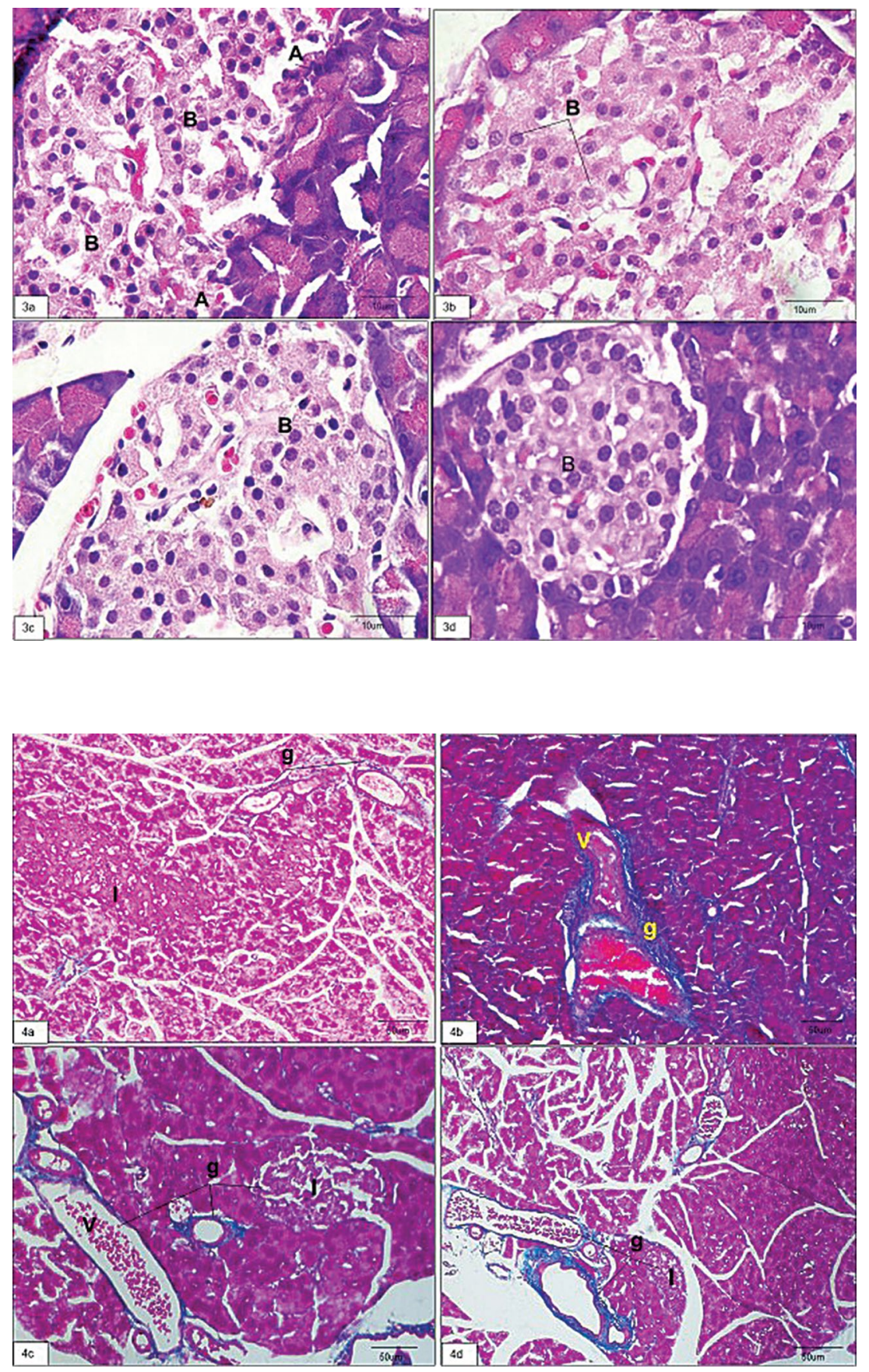

Figure 3. Photomicrographs of transverse sections from the rat pancreas of: a. Group I (control) showing a large islet of Langerhans's. It is composed of mainly red beta-cells $(B)$ and few peripheral dark alpha-cells (A); b. Group II (fed with HFD) showing that most of beta-cells $(B)$ in islet of Langerhans are degranulated with small degenerated nuclei; c. Group III (fed with HFD and virgin olive oil) showing that most of beta-cells $(B)$ in the islet with normal density; d. Group IV (fed with HFD and Nigella sativa seeds) showing normal density of beta-cells (B) as compared with control. H\&E; scale bar $=10 \mu \mathrm{m}$.
Figure 4. Photomicrographs of transverse sections from the rat pancreas of: a. Group I (control) showing fine collagenous fibres (g) around the interlobular vessels and ducts. Fine collagenous fibres appeared also inside and around the islet of Langerhans (I); b. Group II (fed with HFD) showing thick collagenous fibres $(\mathrm{g})$ around a dilated destructed interlobular vessel (V) containing a Large area of haemorrhage; c. Group III (fed with HFD and virgin olive oil) showing a moderate distribution of collagenous fibrous $(\mathrm{g})$ content around the interlobular vessels (V), ducts and islets (I); d. Group I (fed with HFD and Nigella sativa seeds) showing a moderate distribution of collagenous fibrous content $(\mathrm{g})$ around the interlobular vessels (V), ducts and islets (I). Masson's trichrome stain; scale bar $=50 \mu \mathrm{m}$.
HFD and N. sativa seeds, the distribution of collagenous fibrous content (Fig. 4c, 4d) were improved and decreased in thickness as compared with those of Group II.

\section{Electron microscopic result}

Exocrine part. Electron microscopic examination of ultrathin sections from the pancreatic exocrine cells of control rats of Group I showed that the apical cytoplasm contained numerous zymogen granules with variable sizes and shapes (Fig. 5a). The basal cytoplasm contained quantities of ribosome-attached rough endoplasmic reticulum (RER). Some condensing vacuoles containing secretory material of low density were seen in the vicinity of the Golgi apparatus, and a few lysosome-like bodies were detected in the apical cytoplasm of the cell. Mitochondria appeared as oval and rod-shaped bodies in both the apical and basal parts of the cell. The nuclei were smoothly rounded in general and occupied the basal portion of the acinus (Fig. 6a).

Electron microscopic examination of ultrathin sections from the pancreatic exocrine cells of rats of Group II fed with HFD revealed a marked vascular 

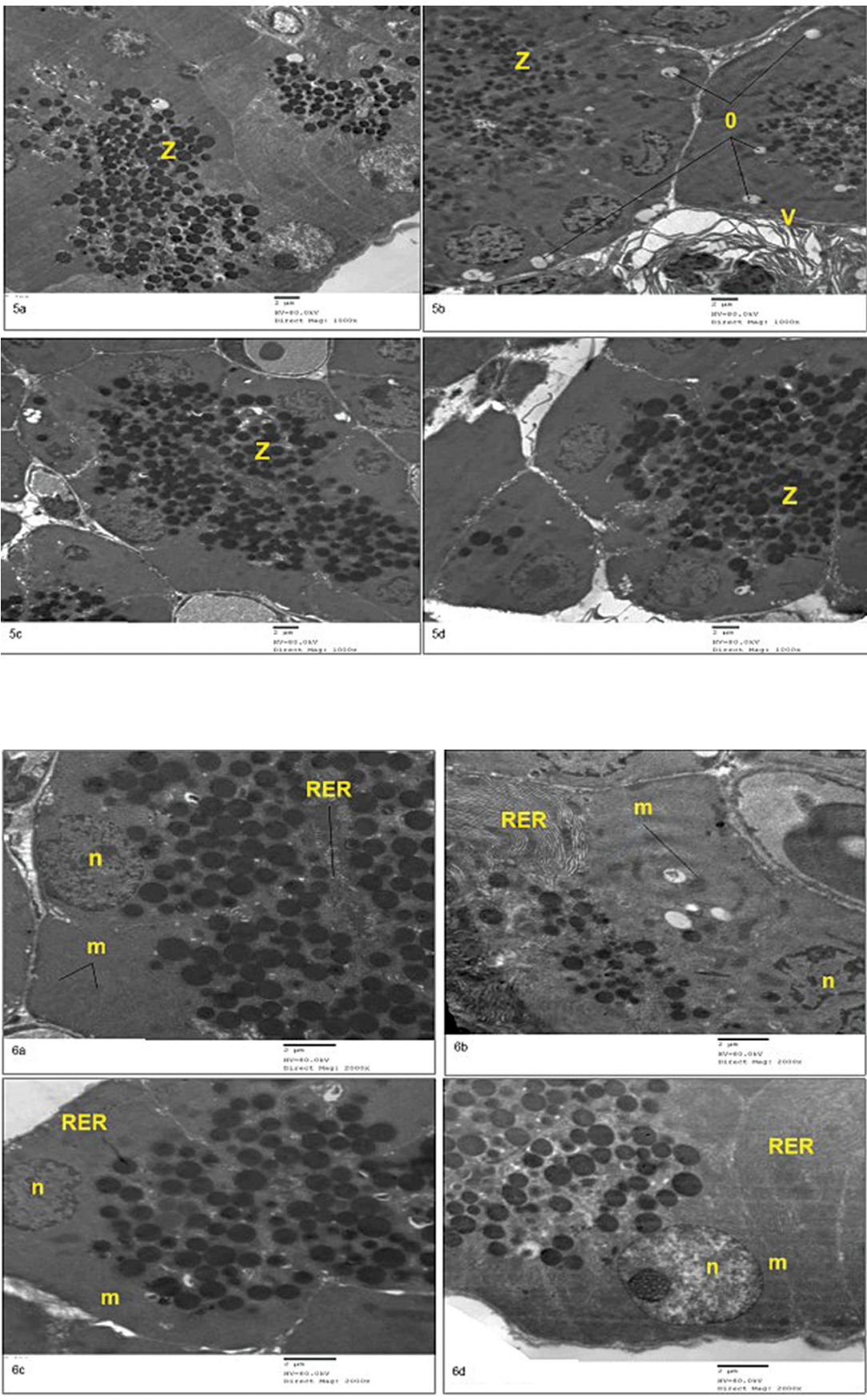

Figure 5. Electron micrographs of ultrathin sections from pancreatic exocrine cells of: a. Group I (control) showed numerous dark zymogen granules (Z) with variable sizes and shapes in the apical cytoplasm; b. Group II (fed with HFD) showed the zymogen granules (Z) are markedly decreased in number and densities, a marked vascular congestion in a destructed blood vessel wall's (V) and phagocytic vacuoles in the cytoplasm (0); c. Group III (fed with HFD and virgin olive oil) showed the zymogen granules (Z) are increased in number and density and nearly similar to the control; d. Group I (fed with HFD and Nigella sativa seeds) showed that the zymogen granules (Z) are markedly increased in number and density similar to control. Double stain; scale bar $=2 \mu m \times 1000$.

Figure 6. Electron micrographs of ultrathin sections from pancreatic exocrine cells of: a. Group I (control) showed the rough endoplasmic reticulum (RER), mitochondria (m). Mitochondria appeared as oval and rod-bodies in both the apical and basal parts of the cell. Showing the rounded nuclei (n) with regular nuclear membranes; b. Group II (fed with HFD) showed the swollen rough endoplasmic reticulum (RER). Showing the nuclei (n) are pyknotic or with irregular outlines. Showing also the mitochondria $(\mathrm{m})$ appeared swollen; c. Group III (fed with HFD and virgin olive oil) showed most of mitochondria $(\mathrm{m})$ and rough endoplasmic reticulum (RER) restored their shapes. Most of nuclei (n) appeared with normal shapes with regular nuclear membranes; d. Group IV (fed with HFD and Nigella sativa seeds) showed most of mitochondria $(\mathrm{m})$ and rough endoplasmic reticulum (RER) restored their shapes. The nuclei (n) appeared with normal shapes with regular nuclear membranes. Double stain; scale bar $=2 \mu m \times 2000$. congestion with partial destruction of the blood vessel's walls. The zymogen granules were markedly decreased in number and densities. The cytoplasm of the acinar cells was full with fat droplets and phagocytic vacuoles (secondary lysosomes). The rodshaped mitochondria appeared swollen (Fig. 5b). The rough endoplasmic reticulum appeared swollen; it took the shape of large spherical to irregular vesicular profiles containing fibrillar materials. The nuclei appeared pyknotic with irregular nuclear membranes
(Fig. 6b). Electron microscopic examination of ultrathin sections from the pancreatic exocrine cells of rats of Group III fed with HFD and virgin olive oil revealed that the zymogen granules were increased in number and density (Fig. 5c). Most of mitochondria and RER restored their shapes. Most of nuclei appeared with normal shapes with regular nuclear membranes. The chromatin matrix restored its normal arrangement and shape. Few fat droplets were present (Fig. 6c). 

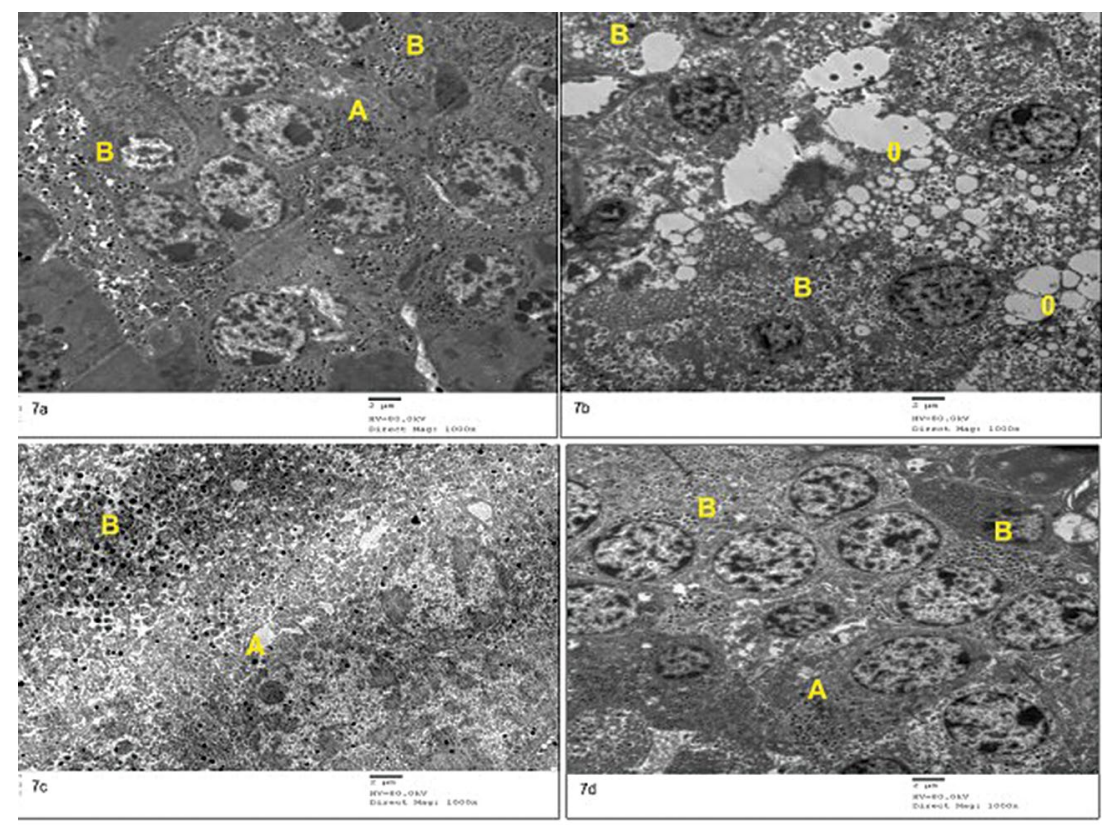

Figure 7. Electron micrographs of ultrathin section from an islet of Langerhans of: a. Group I (control) showed the beta-cells (B) and alpha-cells (A) with their specific endocrine granules. The nuclei of beta-cells contain both hetero and euchromatin. The nuclei of alpha-cells contain small chromatin clumps; b. Group II (fed with HFD) showing marked degranulation of the beta-cells and alpha-cells with degeneration of their nuclei. Showing also a marked vacuolation of the cytoplasm (0), swollen mitochondria $(\mathrm{m})$ and rough endoplasmic reticulum (RER); c. Group III (fed with HFD and virgin olive oil) showing most of beta-cells (B) and alpha-cells (A) restoring the density of the granules and the nuclei are regenerated with normal shape and normal distribution of chromatin matrix. Most of mitochondria and RER appeared as those of the control group. Few cytoplasmic vacuoles are present; d. Group IV (fed with HFD and Nigella sativa seeds) showed that beta-cells (B) and alpha-cells (A) are nearly similar to control. Double stain scale bar $=2 \mu m \times 1000$.

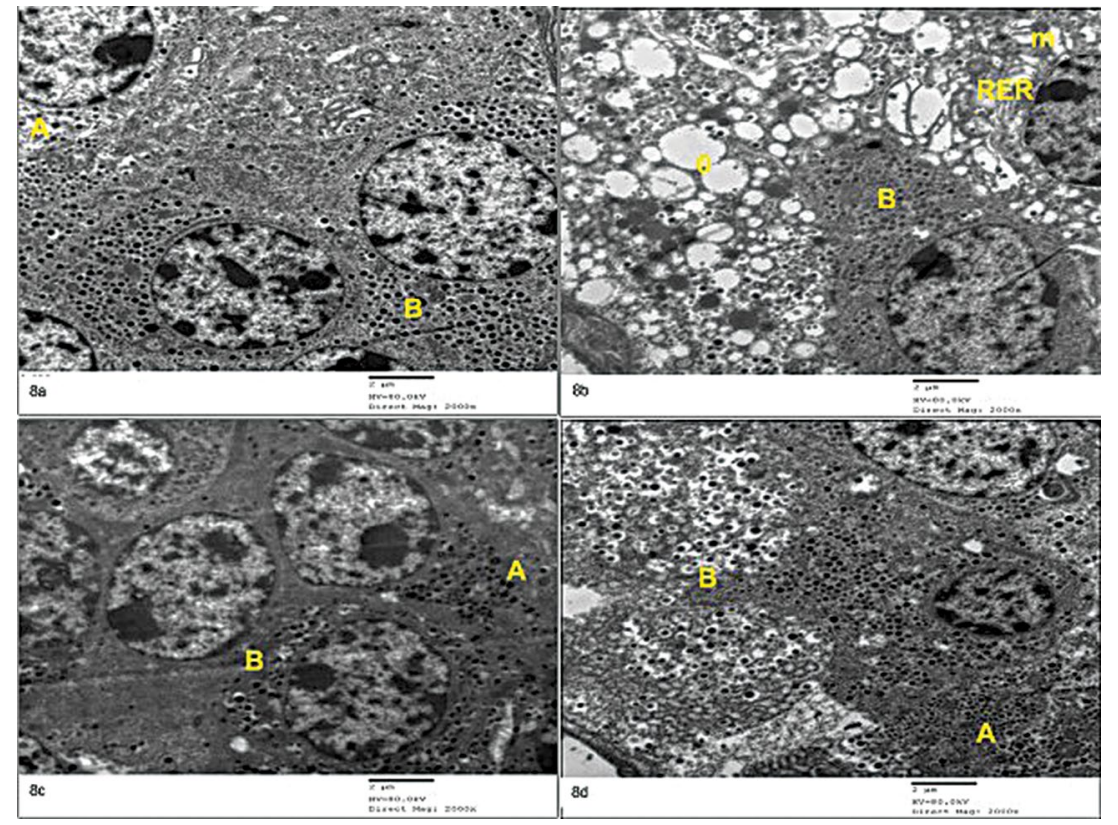

Figure 8. Electron micrographs of ultrathin section from an islet of Langerhans of: a. Group I (control) showing the granules of beta-cells (B) are rounded in shape, contained dark electron dense cores and surrounded by wide electron-lucent halos. Showing the granules of alpha-cells (A) are more numerous and electron dense than the beta-granules and are surrounded by narrower halos; b. Group II (fed with HFD) showing marked degranulation of the beta-cells $(B)$ with degeneration of their nuclei. Showing also a marked vacuolation of the cytoplasm (0); c. Group III (fed with HFD and virgin olive oil) showing most of beta-cells $(B)$ and alpha-cells $(A)$ restoring the density of the granules and the nuclei are regenerated with normal shape and normal distribution of chromatin matrix. Few cytoplasmic vacuoles are present; d. Group IV (fed with HFD and Nigella sativa seeds) showed that beta-cells (B) and alpha-cells $(A)$ are nearly similar to control. Double stain; scale bar $=2 \mu \mathrm{m} \times 2000$.
Electron microscopic examination of ultrathin sections from the pancreatic exocrine cells of rats of Group IV fed with HFD and N. sativa seeds revealed that the zymogen granules were markedly increased in number and density (Fig. 5d) and became similar to those of control group (Fig. 5a). Most of mitochondria and RER restored their shapes. The nuclei appeared with normal shapes with regular nuclear membranes (Fig. 6d).

\section{Endocrine part}

Electron microscopic examination of ultrathin sections from the islets of Langerhans of control rats of Group I (Figs. 7a, 8a) revealed that the islet cells were characterised essentially by the morphological features of their endocrine granules. Granules of beta-cells appeared rounded in shape variable in size and contained homogenous cores, which were separated from the surrounding membrane by wide 
electron-lucent halos. Most of these granules had dark electron dense cores. The nuclei of beta-cells were irregular in outline and contained both hetero and euchromatin. Heterochromatin was mostly attached to the nuclear envelope. The alpha-cells were present in peripheral position beside the acinar cells. Their characteristic granules were more numerous and electron dense than the beta-granules and were surrounded by narrower halos and closely applied limiting membranes. The nuclei were regular in outline with small chromatin clumps.

Electron microscopic examination of ultrathin sections from the islet of Langerhans of rats of Group II fed on HFD revealed that the beta-cells showed multiple signs of degeneration as marked degranulation of the beta-cells and alpha-cells with degeneration of their nuclei and mitochondria and rough endoplasmic reticulum appeared swollen (Figs. 7b, 8b). A marked vacuolation of the cytoplasm was also present.

Electron microscopic examination of ultrathin sections from the islet of Langerhans of rats of Group III fed on HFD and virgin olive oil revealed that most of beta-cells and alpha-cells showing marked signs of improvement as restoring the density of the granules and the nuclei became regenerated with normal shape and normal distribution of chromatin matrix (Figs. 7c, 8c). Most of mitochondria and RER appeared as those of the control group. Few cytoplasmic vacuoles were present.

Electron microscopic examination of ultrathin sections from the islet of Langerhans of rats of Group IV fed on HFD and N. sativa seeds revealed that betaand alpha-cells are nearly similar to the control cells (Figs. 7d, 8d).

\section{DISCUSSION}

\section{Blood analysis}

In the present study, the fasting blood sugar and mean serum amylase levels are increased significantly in G2 rats fed on HFD as compared with the control rats and the serum insulin levels are decreased significantly in G2 rats. These results suggesting that hyperlipidaemia predisposes to pancreatitis and are in agreement with the results of other studies $[11,12]$.

In the present study, the serum lipid profile in hyperlipidaemic rats are favourably modified in G3 fed on virgin olive oil and G4 fed on N. sativa seeds powder, which was characterised by a significant decrease in total cholesterol, LDL-C and triglycerides. Moreover, while N. sativa decreases HDL, virgin olive oil increases significantly HDL. Also a significant decrease in the serum levels of blood glucose and amylase and a significant increase in insulin levels are present in these groups. These results suggest the improvement of the hyperlipidaemic pancreatitis.

These results are in agreement with many authors $[2,15,20]$ who mentioned that the bioactivity of olive tree by product extracts might be related to antioxidant and phenolic composites like oleuropein, hydroxytyrosol, oleuropein aglycone, and tyrosyl. They had shown that oleuropein is related to improved glucose metabolism. The hypoglycaemic and antioxidant effects of oleuropein have been reported in alloxan diabetic rabbits. In streptozotocin (STZ) induced diabetic rats, olive leaf extract decreased serum concentrations of lipids, glucose, uric acid, creatinine, and liver enzymes.

These results are in accordance with many authors $[13,37]$ who mentioned that the N. sativa oil has an antilipidaemic action and this action might due to their ability to stimulate insulin secretion from a stimulatory effect on beta-cell function. The treatment of hypercholesterolaemic rabbits with $\mathrm{N}$. sativa seeds powder or oil showed hypocholesterolaemic and antiatherogenic cardioprotective properties $[3,4]$.

The consumption of olive oil might reduce the risk factors of heart disease by lowering blood cholesterol levels and decreasing LDL-C oxidation and this might also possibly influence inflammatory, thrombotic, hypertensive and vasodilator mechanisms $[7,10]$.

The protective antioxidant effects of olive oil and N. sativa oil was explained [22]. The mechanism of olive oil might be due to the presence of MUFA, oleic acid, vitamin E omega 3, and oleuropein which were responsible for its antioxidant effect. The mechanism of $\mathrm{N}$. sativa is decreasing lipid profile (total cholesterol, triglycerides, LDL-C and VLDL-C) due to the presence of monounsaturated fat and phenols. Nigella sativa oil is rich with conjugated linoleic acid, thioquinone and nigellon dithymoquinone which provide the protective antioxidant effect [22]. A diet supplemented with virgin olive oil can modify pancreatic cell function as assessed by $\mathrm{Ca} 2$ immobilisation and amylase release evoked by secretagogues in rat pancreatic acinar cells [27].

In this study microscopic examination of pancreatic tissues of the rats fed with HFD for 8 weeks showed marked affection of its exocrine and endocrine parts, as marked collagenous thickening of interlobular and intralobular ducts were detected with congestion of dilated intralobular blood vessels. The cytoplasm of the 
pancreatic acini contained many vacuoles and most of their nuclei showed a marked degree of degeneration as they were small, dark and pyknotic. Most of the islets of Langerhans lost their regular outlines with a marked reduction in their sizes and numbers. Most of beta-cells appeared degranulated with small degenerated nuclei. Large areas of haemorrhage with a marked vacuolation appeared in the islets.

These results are in agreement with many studies $[11,35,39]$, which mentioned the role of lipids in progressive pancreatic diseases.

In this study, microscopic examination of pancreatic tissues of the rats fed with HFD with either olive oil or with N. sativa seeds for 8 weeks showed a marked improvement of pancreatic tissue especially in $\mathrm{N}$. sativa group. The collagenous fibres distribution around the ducts, vessels and islets were decreased as compared with hyperlipidaemic group and appeared nearly similar to those of control group. The pancreatic acini were moderately improved in shape and most of them had no vacuolation. Most of nuclei and zymogen granules appeared nearly similar to those of control. The islet of Langerhans appeared somewhat similar to those of the control group with normal density of beta-cells in the central and peripheral regions of the islet.

In this study, electron microscopic examination of the pancreas of hyperlipidaemic rats showed a marked degeneration of both exocrine and endocrine parts. The exocrine part showed a marked vascular congestion, the zymogen granules were markedly decreased in number and densities, the cytoplasm of the acinar cells was full with fat droplets and phagocytic vacuoles, the rough endoplasmic reticulum RER appeared swollen, it took the shape of large spherical to irregular vesicular profiles containing fibrillar materials. The nuclei appeared pyknotic or with irregular outlines. The endocrine part showed that the beta-cells and alpha-cells had multiple signs of degeneration such as marked degranulation of the beta-cells with degeneration of their nuclei. Marked vacuolation of the cytoplasm was present.

The hyperlipidaemia induced by high-fat feeding affected beta-cells functions such as decreasing insulin secretion [35]. Ni et al. (2014) [30] reported case studies of correlation between high blood lipid levels and chronic pancreatitis.

In this study, electron microscopic examination of the pancreas of rats feed on HFD with virgin olive oil or with N. sativa seeds powders showed a marked improvement of exocrine and endocrine parts of the pancreas. The exocrine part showed the zymogen granules were increased in number and density especially with nigella sativa group. Most of nuclei appeared with normal shapes with regular nuclear membranes. The chromatin matrix restored its normal arrangement and shape. Few fat droplets were present. The endocrine part revealed that most of beta-cells and alpha-cells showing marked signs of improvement as restore the density of the granules and the nuclei became regenerated with normal shape and normal distribution of chromatin matrix.

These results were in agreement with Natalicchio et al. (2018) [29], who confirmed the positive effects of the main polyphenols contained in extra virgin olive oil on beta-cell function and survival suggesting that extra virgin enriched with these compounds might improve insulin secretion and promoted glycaemic control in type 2 diabetic patients.

Many studies confirmed the ability of $\mathrm{N}$. sativa to preserve pancreatic beta-cell integrity, to induce lipid peroxidation, and to increase antioxidant defence system activity [28]. However, this latter suggestion may be contradictory as lipid peroxidation is the primary marker of oxidative stress. The effects of $\mathrm{N}$. sativa on oxidative stress and cell damage in STZ-induced diabetic rats. They suggested that N. sativa treatment exerted a therapeutic protective effect in diabetes by decreasing oxidative stress and preserving pancreatic cell integrity $[23,24]$.

\section{CONCLUSIONS}

In this study, the biochemical results were paralleled to the histological and ultrastructural results; therefore, it could be concluded that virgin olive oil and N. sativa seeds had antihyperlipidaemic and hypoglycaemic effects and they could protect the pancreas from hyperlipidaemia-induced injury and the daily consumption of virgin olive oil and $\mathrm{N}$. sativa seeds in the diets is highly recommended.

\section{Acknowledgements}

This project was funded by the Deanship of Scientific Research (DRS), King Abdulaziz University, Jeddah, under grant no. (G-108-248-1439). The authors, therefore, acknowledge with thanks DSR technical and financial support. Principal investigator, Prof. Laila M. Aboul-Mahasen. 


\section{REFERENCES}

1. Ibrahim A. Effects of olive oil on lipid profiles and blood glucose in type2 diabetic patients. Int J Diabetes Metab. 2011; 19: 19-22.

2. Al-Azzawie HF, Alhamdani MSS. Hypoglycemic and antioxidant effect of oleuropein in alloxan-diabetic rabbits. Life Sci. 2006; 78(12): 1371-1377, doi: 10.1016/j.Ifs.2005.07.029, indexed in Pubmed: 16236331

3. Al-Logmani A, Zari T. Long-term effects of Nigella sativa L. oil on some physiological parameters in normal and streptozotocin-induced diabetic rats. J Diabetes Mellitus. 2011; 01(03): 46-53, doi: $10.4236 / j \mathrm{dm} .2011 .13007$.

4. Al-Naqeep G, Al-Zubairi AS, Ismail M, et al. Antiatherogenic Potential of Nigella sativa Seeds and Oil in Diet-Induced Hypercholesterolemia in Rabbits. Evid Based Complement Alternat Med. 2011; 2011: 213628, doi: 10.1093/ecam/neq071, indexed in Pubmed: 21792359.

5. Auti SS, Thakar AB, Shukla VJ, et al. Assessment of Lekhana Basti in the management of hyperlipidemia. Ayu. 2013; 34(4): 339-345, doi: 10.4103/0974-8520.127683, indexed in Pubmed: 24696569.

6. Azzubaidi MS, Saxena AK, Talib NA, et al. Protective effect of treatment with black cumin oil on spatial cognitive functions of rats that suffered global cerebrovascular hypoperfusion. Acta Neurobiol Exp. 2012; 72(2): 154-165, indexed in Pubmed: 22810217.

7. Baggio G, Pagnan A, Muraca M, et al. Olive-oil-enriched diet: effect on serum lipoprotein levels and biliary cholesterol saturation. Am J Clin Nutr. 1988; 47(6): 960-964, doi: 10.1093/ajcn/47.6.960, indexed in Pubmed: 3132035.

8. Bancroft JD, Floyd AD, Suvarna SK. Bancroft's Theory and Practice of Histological Techniques. 2013.

9. Burits M, Bucar F. Antioxidant activity of Nigella sativa essential oil. Phytother Res. 2000; 14(5): 323-328, indexed in Pubmed: 10925395.

10. Covas MI. Olive oil and the cardiovascular system. Pharmacol Res. 2007; 55(3): 175-186, doi: 10.1016/j.phrs.2007.01.010, indexed in Pubmed: 17321749

11. de Pretis N, Amodio A, Frulloni L. Hypertriglyceridemic pancreatitis: Epidemiology, pathophysiology and clinical management. United Eur Gastroenterol J. 2018; 6(5): 649-655, doi: 10.1177/2050640618755002, indexed in Pubmed: 30083325.

12. Domínguez-Muñoz JE, Jünemann F, Malfertheiner P. Hyperlipidemia in acute pancreatitis. Cause or epiphenomenon? Int J Pancreatol. 1995; 18(2): 101-106, doi: 10.1007/BF02785883, indexed in Pubmed: 8530825.

13. Fararh KM, Atoji $Y$, Shimizu $Y$, et al. Isulinotropic properties of Nigella sativa oil in Streptozotocin plus Nicotinamide diabetic hamster. Res Vet Sci. 2002; 73(3): 279-282, indexed in Pubmed: 12443686.

14. Farrag ARH, Mahdy KA, Abdel Rahman GH, et al. Protective effect of Nigella sativa seeds against lead-induced hepatorenal damage in male rats. Pak J Biol Sci. 2007; 10(17): 2809-2816, indexed in Pubmed: 19090181.

15. Gonzalez M, Zarzuelo A, Gamez MJ, et al. Hypoglycemic activity of olive leaf. Planta Med. 1992; 58(6): 513-515, doi: 10.1055/s2006-961538, indexed in Pubmed: 1484890.

16. Harris R. Electron microscopy in biologya practical approach. 1991.

17. Haseena S, Aithal M, Das KK, et al. Effect of nigella sativa seed powder on testosterone and LH levels in sterptozotocine induced diabetes male albino rats. J Pharmaceutical Sci Res. 2015; 7(4): 234-237.

18. Hayat MA. Principles and techniques of electron microscopy. Biological applications: Edward Arnold. 1981

19. Hosseini M, Mohammadpour T, Karami R, et al. Effects of the hydro-alcoholic extract of Nigella sativa on scopolamine-induced spatial memory impairment in rats and its possible mechanism. Chin J Integr Med. 2015; 21(6): 438-444, doi: 10.1007/s11655014-1742-5, indexed in Pubmed: 24584756.

20. Jemai H, El Feki A, Sayadi S. Antidiabetic and antioxidant effects of hydroxytyrosol and oleuropein from olive leaves in alloxan-diabetic rats. J Agric Food Chem. 2009; 57(19): 8798-8804, doi: 10.1021/ jf901280r, indexed in Pubmed: 19725535.

21. Kacem R, Meraihi Z. Effects of essential oil extracted from Nigella sativa (L.) seeds and its main components on human neutrophil elastase activity. Yakugaku Zasshi. 2006; 126(4): 301-305, doi: 10.1248/yakushi.126.301, indexed in Pubmed: 16596021.
22. Kafi LA. A comparative study between olive oil and Nigella Sativa oil in treatment of hyperlipidemia induced in male albino mice The Iraqi Journal of Veterinary Medicine. 2014; 38(2): 123-127.

23. Kanter M, Coskun O, Korkmaz A, et al. Effects of Nigella sativa on oxidative stress and beta-cell damage in streptozotocin-induced diabetic rats. Anat Rec A Discov Mol Cell Evol Biol. 2004; 279(1): 685-691, doi: 10.1002/ar.a.20056, indexed in Pubmed: 15224410.

24. Kanter M, Meral I, Yener Z, et al. Partial regeneration/proliferation of the beta-cells in the islets of Langerhans by Nigella sativa $L$. in streptozotocin-induced diabetic rats. Tohoku J Exp Med. 2003; 201(4): 213-219, doi: 10.1620/tjem.201.213, indexed in Pubmed: 14690013.

25. Laila M, Aboul-Mahasen A, Rasha A, et al. The Ameliorative Effect of Olive Oil in The Biochemical And Histopathological Changes of The Rat Kidney Induced By Hyperlipidemia International. J Pharmaceutical Phytopharmacological Res. 2017; 7(4): 34-42.

26. Lavelli V. Comparison of the antioxidant activities of extra virgin olive oils. J Agric Food Chem. 2002; 50(26): 7704-7708, doi: 10.1021/jf020749o, indexed in Pubmed: 12475292.

27. Martínez MA, Lajas Al, Yago MD, et al. Dietary virgin olive oil enhances secretagogue-evoked calcium signaling in rat pancreatic acinar cells. Nutrition. 2004; 20(6): 536-541, doi: 10.1016/j. nut.2004.03.018, indexed in Pubmed: 15165616.

28. Meral I, Yener Z, Kahraman T, et al. Effect of Nigella sativa on glucose concentration, lipid peroxidation, anti-oxidant defence system and liver damage in experimentally-induced diabetic rabbits. J Vet Med A Physiol Pathol Clin Med. 2001; 48(10): 593-599, indexed in Pubmed: 11848252.

29. Natalichio A, Spagnuolo R, Marrano N, et al. Effects of extra virgin olive oil polyphenols on pancreatic beta-cell function and survival. Diabetes. 2018; 67(Supplement 1), doi: 10.2337/db18-2147-p.

30. Ni Q, Yun L, Xu R, et al. Correlation between blood lipid levels and chronic pancreatitis: a retrospective case-control study of 48 cases. Medicine (Baltimore). 2014; 93(28): e331, doi: 10.1097/ MD.0000000000000331, indexed in Pubmed: 25526493.

31. Paniagua JA, Gallego de la Sacristana A, Romero I, et al. Monounsaturated fat-rich diet prevents central body fat distribution and decreases postprandial adiponectin expression induced by a carbohydrate-rich diet in insulin-resistant subjects. Diabetes Care. 2007; 30(7): 1717-1723, doi: 10.2337/dc06-2220, indexed in Pubmed: 17384344.

32. Perez-Jimenez F, Alvarez de Cienfuegos G, Badimon L, et al. International conference on the healthy effect of virgin olive oil. Eur J Clin Invest. 2005; 35(7): 421-424, doi: 10.1111/j.13652362.2005.01516.x, indexed in Pubmed: 16008542.

33. Perona JS, Cabello-Moruno R, Ruiz-Gutierrez V. The role of virgin olive oil components in the modulation of endothelial function. J Nutr Biochem. 2006; 17(7): 429-445, doi: 10.1016/j.jnutbio.2005.11.007, indexed in Pubmed: 16481154.

34. Tiruppur Venkatachallam SK, Pattekhan H, Divakar S, et al. Chemical composition of Nigella sativa L. seed extracts obtained by supercritical carbon dioxide. J Food Sci Technol. 2010; 47(6): 598-605, doi: 10.1007/s13197-010-0109-y, indexed in Pubmed: 23572692.

35. Valdivielso P, Ramírez-Bueno A, Ewald N. Current knowledge of hypertriglyceridemic pancreatitis. Eur J Intern Med. 2014; 25(8): 689-694, doi: 10.1016/j.ejim.2014.08.008, indexed in Pubmed: 25269432

36. Visioli $F$, Galli $C$. The effect of minor constituents of olive oil on cardiovascular disease: new findings. Nutr Rev. 1998; 56(5 Pt 1): 142-147, doi: 10.1111/j.1753-4887.1998.tb01739.x, indexed in Pubmed: 9624884.

37. Weidenheim KM, Hinchey WW, Campbell WG. Hyperinsulinemic hypoglycemia in adults with islet-cell hyperplasia and degranulation of exocrine cells of the pancreas. Am J Clin Pathol. 1983; 79(1): 14-24, doi: 10.1093/ajcp/79.1.14, indexed in Pubmed: 6336883.

38. Woods SC, Seeley RJ, Rushing PA, et al. A controlled high-fat diet induces an obese syndrome in rats. J Nutr. 2003; 133(4): 1081-1087, doi: 10.1093/jn/133.4.1081, indexed in Pubmed: 12672923.

39. Yadav D, Pitchumoni CS. Issues in hyperlipidemic pancreatitis. J Clin Gastroenterol. 2003; 36(1): 54-62, doi: 10.1097/00004836200301000-00016, indexed in Pubmed: 12488710. 